\title{
Microstructure, mechanical behaviour and fracture of pure tungsten wire after different heat treatments
}

Zhao, P.; Riesch, J.; Höschen, T.; Almanstötter, J.; Balden, M.; Coenen, J. W.; Himml, R.; Pantleon, Wolfgang; von Toussaint, U.; Neu, R.

Published in:

International Journal of Refractory Metals and Hard Materials

Link to article, DOI:

10.1016/j.ijrmhm.2017.06.001

Publication date:

2017

Document Version

Peer reviewed version

Link back to DTU Orbit

Citation (APA):

Zhao, P., Riesch, J., Höschen, T., Almanstötter, J., Balden, M., Coenen, J. W., Himml, R., Pantleon, W., von Toussaint, U., \& Neu, R. (2017). Microstructure, mechanical behaviour and fracture of pure tungsten wire after different heat treatments. International Journal of Refractory Metals and Hard Materials, 68, 29-40.

https://doi.org/10.1016/j.ijrmhm.2017.06.001

\section{General rights}

Copyright and moral rights for the publications made accessible in the public portal are retained by the authors and/or other copyright owners and it is a condition of accessing publications that users recognise and abide by the legal requirements associated with these rights.

- Users may download and print one copy of any publication from the public portal for the purpose of private study or research.

- You may not further distribute the material or use it for any profit-making activity or commercial gain

- You may freely distribute the URL identifying the publication in the public portal 


\section{Microstructure, mechanical behaviour and fracture of pure tungsten wire}

after different heat treatments

\section{P. Zhao ${ }^{\mathrm{a}, \mathrm{b}}$, J. Riesch ${ }^{\mathrm{b},{ }^{*}}$, T. Höschen ${ }^{\mathrm{b}}$, J. Almanstötter, M. Balden ${ }^{\mathrm{b}}$, J.W. Coenen ${ }^{\mathrm{d}}$, R. Himml',} W. Pantleon ${ }^{e}$, U. von Toussaint ${ }^{b}$ and R. Neu ${ }^{b, f}$

a) Department of Mechanical and Mechatronics Engineering, University of Waterloo, N2L 3G1, Waterloo, Canada

b) Max-Planck-Institut für Plasmaphysik, 85748 Garching, Germany

c) OSRAM GmbH, SP PRE PLM DMET, 86830 Schwabmünchen, Germany

d) Forschungszentrum Jülich $\mathrm{GmbH}$, Institut für Energie- und Klimaforschung - Plasmaphysik, Partner of the Trilateral Euregio Cluster (TEC), 52425 Jülich, Germany

e) Section of Materials and Surface Engineering, Department of Mechanical Engineering, Technical University of Denmark, 2800 Kgs. Lyngby, Denmark

f) Fakultät für Maschinenbau, Technische Universität München, 85748 Garching, Germany

*corresponding author: johann.riesch@ipp.mpg.de

\section{Abstract}

Plastic deformation of tungsten wire is an effective source of toughening tungsten fibre-reinforced tungsten composites $\left(\mathrm{W}_{\mathrm{f}} / \mathrm{W}\right)$ and other tungsten fibre-reinforced composites. To provide a reference for optimization of those composites, unconstrained pure tungsten wire is studied after various heat treatments in terms of microstructure, mechanical behaviour and fracture mode. Recrystallization is already observed at a relatively low temperature of $1273 \mathrm{~K}$ due to the large driving force caused by a high dislocation density. Annealing for 30 minutes at $1900 \mathrm{~K}$ also leads to recrystallization, but causes a rather different microstructure. As-fabricated wire and wire recrystallized at $1273 \mathrm{~K}$ for 3 hours show fine grains with a high aspect ratio and a substantial plastic deformability: a clearly defined tensile strength, high plastic work, similar necking shape, and the characteristic knife-edge-necking of individual grains on the fracture surface. While the wire recrystallized at $1900 \mathrm{~K}$ displays large, almost equiaxed grains with low aspect ratios as well as distinct brittle properties. Therefore, it is suggested that a high aspect ratio of the grains is important for the ductile behaviour of tungsten wire and that embrittlement is caused by the loss of the preferable elongated grain structure rather than by recrystallization. In addition, a detailed evaluation of the plastic deformation behaviour during tensile test gives guidance to the design and optimization of tungsten fibre-reinforced composites.

Keywords: tungsten, wire, tungsten fibre-reinforced tungsten, tension test, recrystallization

\section{Introduction}

Due to its very high melting point and superior high temperature strength, tungsten is an attractive material for high temperature components, including the plasma-facing components of fusion reactors [1]. However, due to its inherent brittleness and its susceptibility to embrittlement during operation, 
toughening of tungsten is necessary for this purpose [2]. Recently, the concept of reinforcing tungsten with tungsten wire has been proposed where toughening is achieved by extrinsic mechanisms of energy dissipation induced by the interaction between the wire, the matrix and the interface layer [38]. These mechanisms have been utilized in ceramic matrix composites (CMC) since the 1980s [9-11]. In the case of tungsten fibre-reinforced tungsten composites $\left(W_{f} / W\right)$, the possible plastic deformation of tungsten wire (used as fibres) $[12,13]$ provides an additional effective method of energy dissipation $[6,14]$. The toughening effect caused thereby has been estimated based on experimental tensile data showing that the mechanical behaviour of the wire has a strong influence. Therefore, a detailed investigation of unconstrained pure tungsten wire, with special attention to the energy consumed by plastic deformation of the wire (plastic work) and the necking geometry (which are both rarely reported in literature), will facilitate the optimization of $W_{f} / W$ and other tungsten fibre-reinforced composites, like tungsten fibre-reinforced Cu composites [15, 16], Zr-based metallic glass composites [17] and aluminium composites [18].

Bulk tungsten materials show brittleness below the ductile-to-brittle transition temperature of about 500-900 K (depending on microstructure, composition and testing conditions) and embrittlement by recrystallization [19]. Heavily worked, doped, as well as pure tungsten wires behave quite different and fracture in a ductile manner even at room temperature [20]. There have been many reports on the microstructural development of doped tungsten wires during annealing, which is particularly characterized by the preservation of grains with a high aspect ratio due to the dopants pinning the grain boundaries $[12,13,21]$. On the other hand, studies of pure tungsten wire addressing the question of microstructural evolution and embrittlement by annealing are rare.

In this study, pure tungsten wires with different thermal history were tensile tested and investigated regarding microstructural development, mechanical behaviour (plastic work, strength and necking geometry), fracture properties and the relationships between them. Knowledge concerning the necking geometry can provide an idea for an optimal debonding length, while determination of plastic work allows an estimation of the toughening effect, thereby assisting the design and optimization of $\mathrm{W}_{\mathrm{f}} / \mathrm{W}$ or other tungsten fibre-reinforced composites.

\section{Experimental}

One spool of pure tungsten ${ }^{1}$ wire with a diameter of $150 \mu \mathrm{m}$ was received from OSRAM GmbH, Schwabmünchen (company term: K-Draht Typ B). Beside as-fabricated wire, two other batches were produced. One batch was heated to a temperature of $1273 \mathrm{~K}$ and annealed for 3 hours. In the following, this batch is referred to as low-temperature heat-treated wire (L-heated wire). Another batch was heated to the higher temperature of $1900 \mathrm{~K}$ and annealed for $30 \mathrm{~min}$. This batch is referred to as hightemperature heat-treated wire (H-heated wire). Both heat treatments were done in a molybdenum (Lheated wire) and tungsten ( $\mathrm{H}$-heated wire) based vacuum furnace to avoid oxidation. The microstructures of the as-fabricated, the L-heated and the $\mathrm{H}$-heated wires were investigated using a

\footnotetext{
199.99 purity according to manufacturer specifications
} 
scanning electron microscope (SEM; Helios Nanolab 600, FEI) with an annular solid state backscatter electron (BSE) detector. Both cross-sections and longitudinal sections, were prepared by standard metallographic procedures and investigated by electron channelling contrast providing different brightness depending on the crystallographic orientation and local defects. A first assessment of the grain geometries in the cross-section was achieved by manually correlating with the scale of the sections using the software imageJ [22]. Only grains showing a distinct grain boundary are taken into account. Additionally, longitudinal sections were examined by electron backscatter diffraction (EBSD; HKL Nordlys II, Channel 5-Software). For each kind of wire, an orientation map of about $7000 \mu \mathrm{m}^{2}$ (asfabricated), $5000 \mu \mathrm{m}^{2}$ (L-heated) and $6600 \mu \mathrm{m}^{2}$ (H-heated) was acquired with a step size of $0.25 \mu \mathrm{m}$. About $90 \%$ of the pixels in the patterns were successfully indexed by the software. The acquired orientation maps were post-processed by assigning the average orientation of the neighbouring pixels to an unindexed pixel, if seven or more neighbouring pixels showed the same orientation. The orientation maps obtained by EBSD were used to get a first estimation of the grain sizes in the longitudinal direction by using imageJ and refined by quantitative analysis of the orientation data. The texture of the wires was determined from pole figures calculated from the orientations acquired by EBSD.

Uniaxial tensile tests were conducted by using a universal testing machine (TIRA Test 2820) to acquire stress-strain curves. A sketch of the testing machine is shown in Figure 1. The wires were cut into 80 $\mathrm{mm}$ long pieces. Both ends of such a tungsten wire specimen were covered by glue (UHU Plus endfest $300)$ to protect the ends from being damaged by the clamps and to provoke the sample to neck and crack in the central part. The free length was about $30 \mathrm{~mm}$. Vertical alignment of the samples was achieved by adjusting the bottom clamp. The tensile tests were started with a pre-load of $5 \mathrm{~N}$ and conducted in a displacement-controlled mode at a cross head speed of $5 \mu \mathrm{m} / \mathrm{s}$. The force was recorded by a $200 \mathrm{~N}$ load cell. The elongation of the sample was measured by a laser-speckle extensometer (LSE$4000 \mathrm{DE})$ as indicated in Figure 1. Two spots on the sample with a distance of about $16 \mathrm{~mm}$ are illuminated by the laser system. The light is reflected on the optically rough wire surface and interfere with itself, resulting in a characteristic speckle pattern which is recorded by a CCD line camera (Sony $X D-E S 50)$. From the speckle movement, the elongation of the wire inside the measuring length is calculated. The gauge length thus corresponds to the laser spot distance. If the wire fractures between the two laser spots, both a uniform and a localized elongation (e.g. due to necking preceding fracture), are recorded by the laser-speckle extensometer. If the fracture occurs outside the measuring length, only the uniform deformation is detected. 


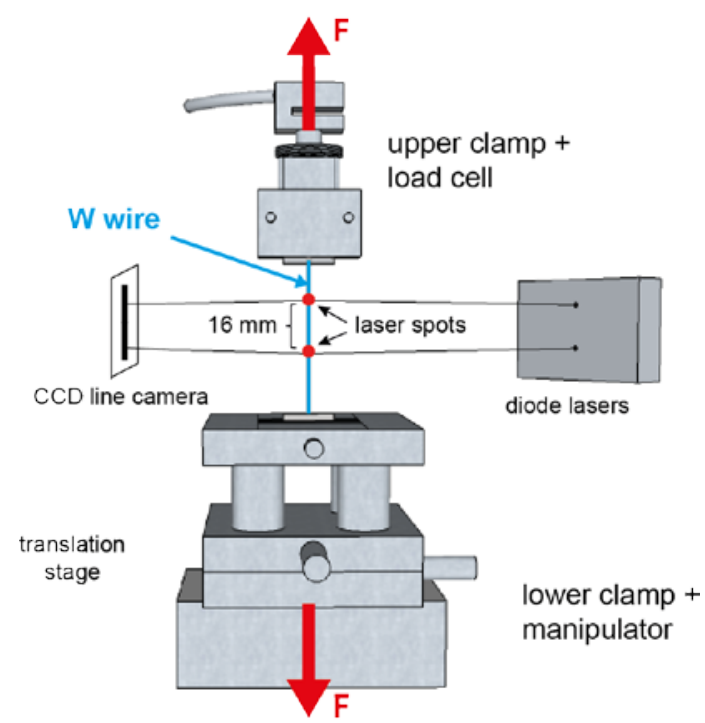

Figure 1. A schematic diagram of the tensile testing machine where a laser-speckle extensometer is used to measure the elongation of a small sample.

Finally, the fracture surfaces were analysed by SEM and the geometry of the necking zone was characterized by a Confocal Laser Scanning Microscope (CLSM; OLYMPUS LEXT OLS 4000). By the combination of in-focus images at different heights, the confocal microscope allows images to be acquired with depth sensitivity. As the in-focus information from the laser provides a height value, the non-planar geometry of the necking region can be quantified. For this examination, the samples were put on a sample holder with the wire axis aligned parallel to the $\mathrm{x}$-axis and roughly horizontal. The obtained 3D data were precisely levelled afterwards by a two-point method along the wire axis.

\section{Results}

\subsection{Microstructure}

Typical cross-sections and longitudinal sections of the as-fabricated wire are shown in Figure 2 and Figure 3, respectively. The contrast depends on the local grain orientation. This contrast is sensitive to subgrain boundaries with a misorientation below $1^{\circ}[23$ ]. In the cross-section (Figure 2), bended grains forming a curled structure are observed. These structures are also known as "Van Gogh sky structures" for their similarity with his style used in painting sky [24]. The grains are not equiaxed and have sizes in the range of $(0.1-0.4) \times(0.5-1) \mu \mathrm{m}^{2}$ based on Figure 2 (right) (Note that all sizes reported in the observed sections are Feret diameters). The longitudinal section, shown in Figure 3, displays extremely elongated grains. In the interior of the grains, significant changes in contrast can be detected, which are caused by elastic strains or defects, dislocations, and dislocation boundaries, indicating the presence of a high dislocation density (see Figure $3 \mathrm{~d}$ ). A comparison between the centre and the edge of an as-fabricated wire is shown in Figure $3 \mathrm{~b} / \mathrm{c}$. The edge region was recorded $10 \mu \mathrm{m}$ from the outer edge of the polished surface to minimize the influence of preparation effects (rounded outer edge of the wire at the transition to the mould). Grains at the edge seem to have fewer dislocations. The high 
amount of dislocations makes it difficult to reveal grain boundaries and determine the length and the aspect ratio of the grains. Therefore, this information is gained from EBSD. From the orientation data, grains were detected as areas with continuous orientation separated by grain boundaries with orientation differences larger than $10^{\circ}$. Figure 4 a shows the longitudinal section where individual grains are represented by unique, but arbitrary colours. Based on this figure, the grain size along the wire drawing direction was estimated to be $10-40 \mu \mathrm{m}$. It should be noted that the length along wire direction could be underestimated as the curling might have bent the grains out of plane of observation. The $\{110\}$ pole figure in Figure $4 \mathrm{~b}$ demonstrates a pronounced texture, with $a<110\rangle$ direction parallel to the wire axis. The pole figure also shows a continuous distribution of (other) $\{110\}$ poles along a ring under the expected angle of $60^{\circ}$ which confirms the existence of a $\{110\}$ fibre texture.
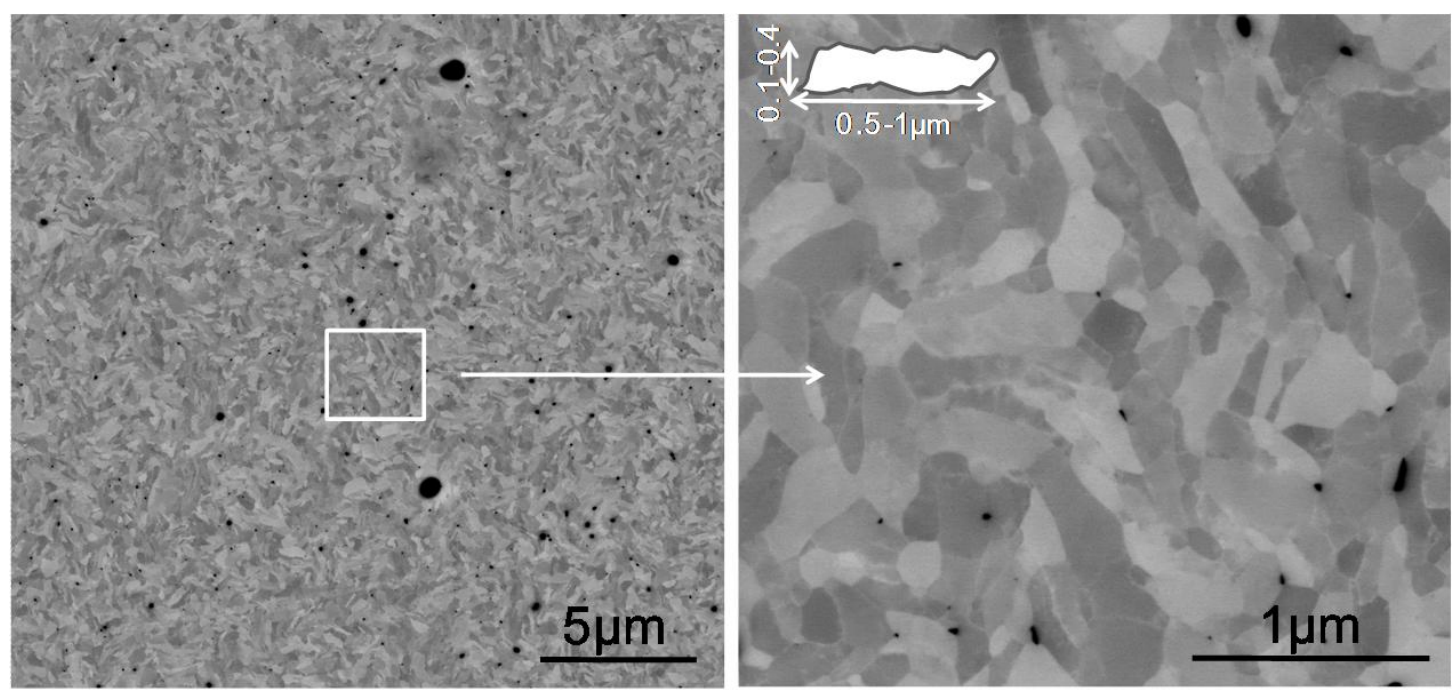

Figure 2. Cross-section of the as-fabricated wire captured in BSE mode in SEM (channelling contrast). 

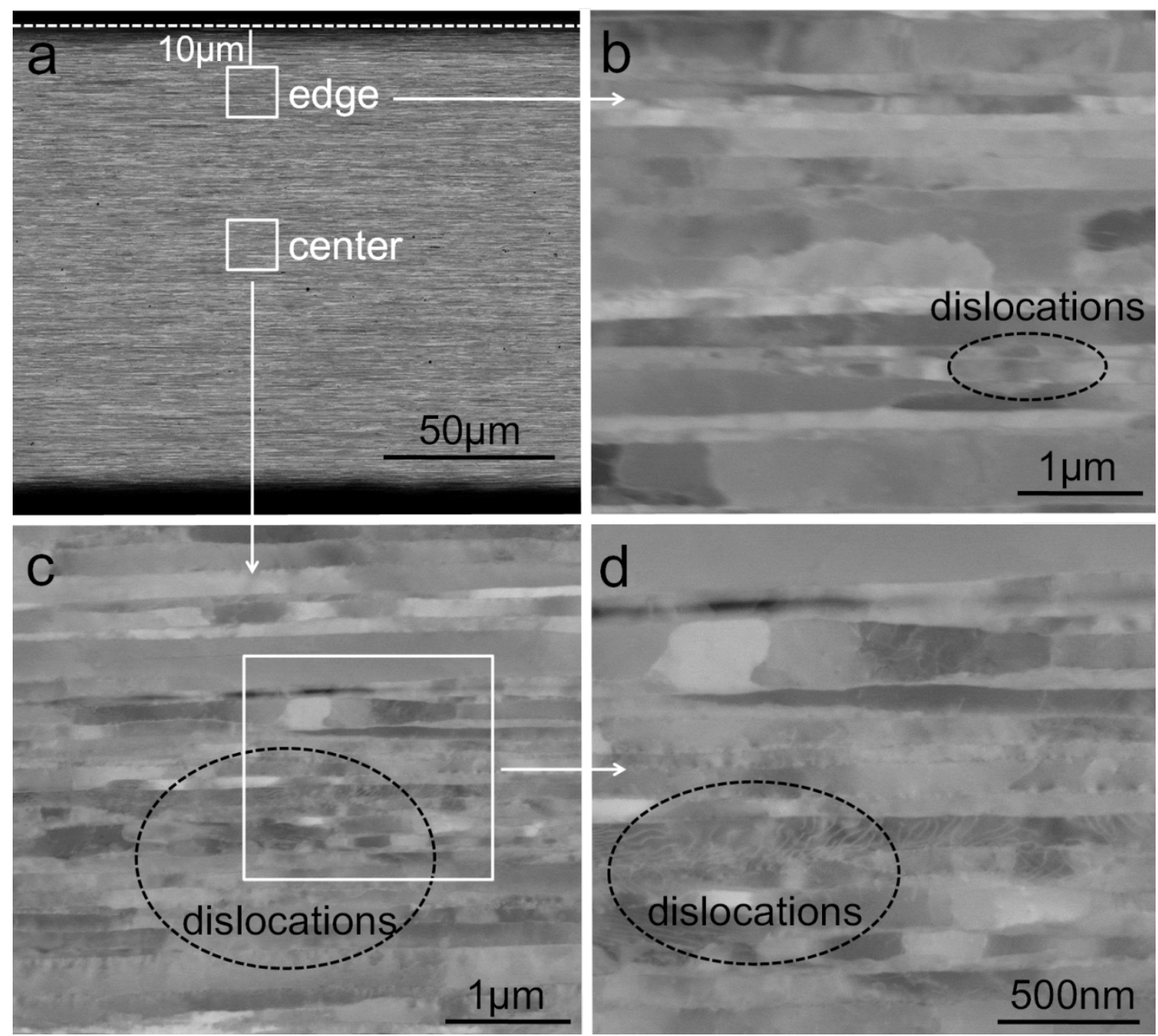

Figure 3. Longitudinal section of the as-fabricated wire captured in BSE mode in SEM including (a) an overview, (b) an image of the edge area, (c) an image of the central area, and (d) a magnified image of the central area.

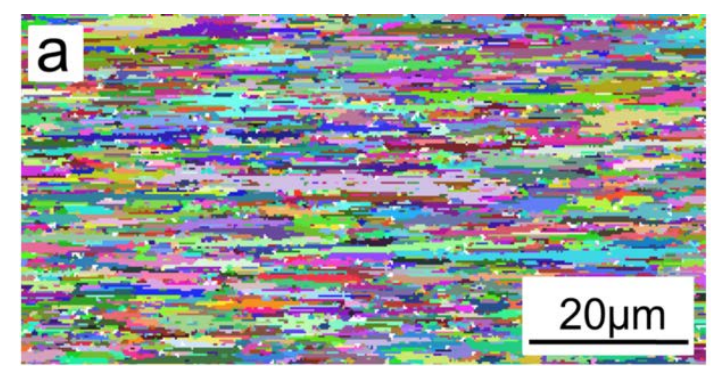

b

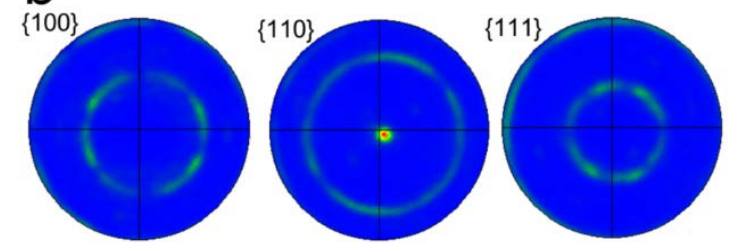

Figure 4. Longitudinal section of the as-fabricated wire obtained by EBSD: (a) grain map with grains separated from others by boundaries with misorientation angles larger than $10^{\circ}$ shown in arbitrary 
colours and (b) calculated $\{100\},\{110\}$ and $\{111\}$ pole figures with wire axis in centre (slightly misaligned as the measured surface is not ideally aligned or exactly parallel to the wire axis).

Figure 5 and Figure 6 show the cross-section and the longitudinal section of a typical L-heated (1273 K) wire, respectively. The grains in the cross-section are equiaxed and curling is no longer observed. Based on Figure 5 (right), the grain size is in the range of (0.3-1.5) $\mu \mathrm{m}$ in the directions perpendicular to the wire axis. The longitudinal section shows elongated grains with nearly complete removal of dislocation structures and many transverse grain or subgrain boundaries. Comparing the centre and edge in Figure $6 \mathrm{~b} / \mathrm{c}$, no significant differences can be observed. The grain map of the longitudinal section obtained by EBSD (based on a minimal misorientation angle between grains of $10^{\circ}$ ) shown in Figure 7 a, allows an estimation of the grain size along the wire direction of approximately 10-90 $\mu \mathrm{m}$. The grains are coarsened and apparently longer compared to the as-fabricated condition. This increase in length might be a consequence of the vanished curling and therefore full alignment of the grains to the fibre axis. The $\{110\}$ pole figure in Figure $7 \mathrm{~b}$ indicates also a fibre texture similar to the as-fabricated sample, with a $<110>$ direction parallel to the wire axis.
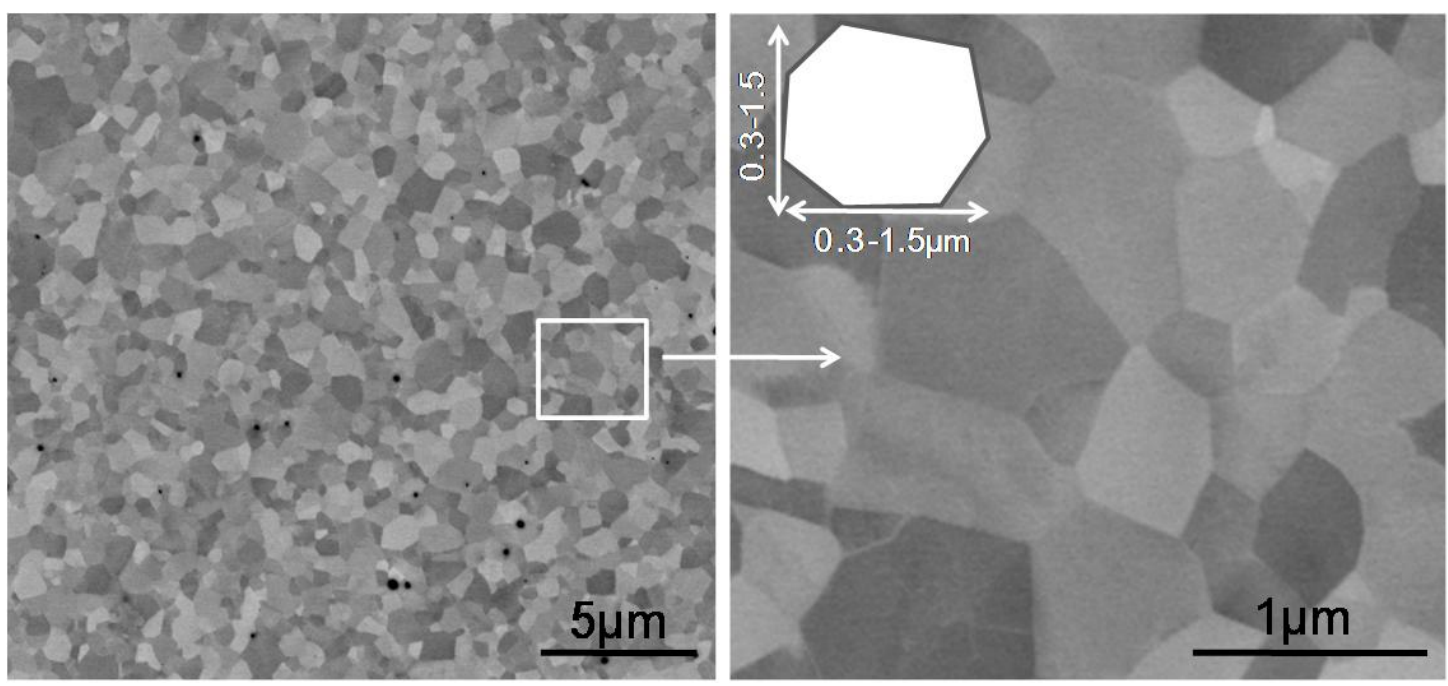

Figure 5. Cross-section of the L-heated wire captured by BSE mode in SEM (channelling contrast). 


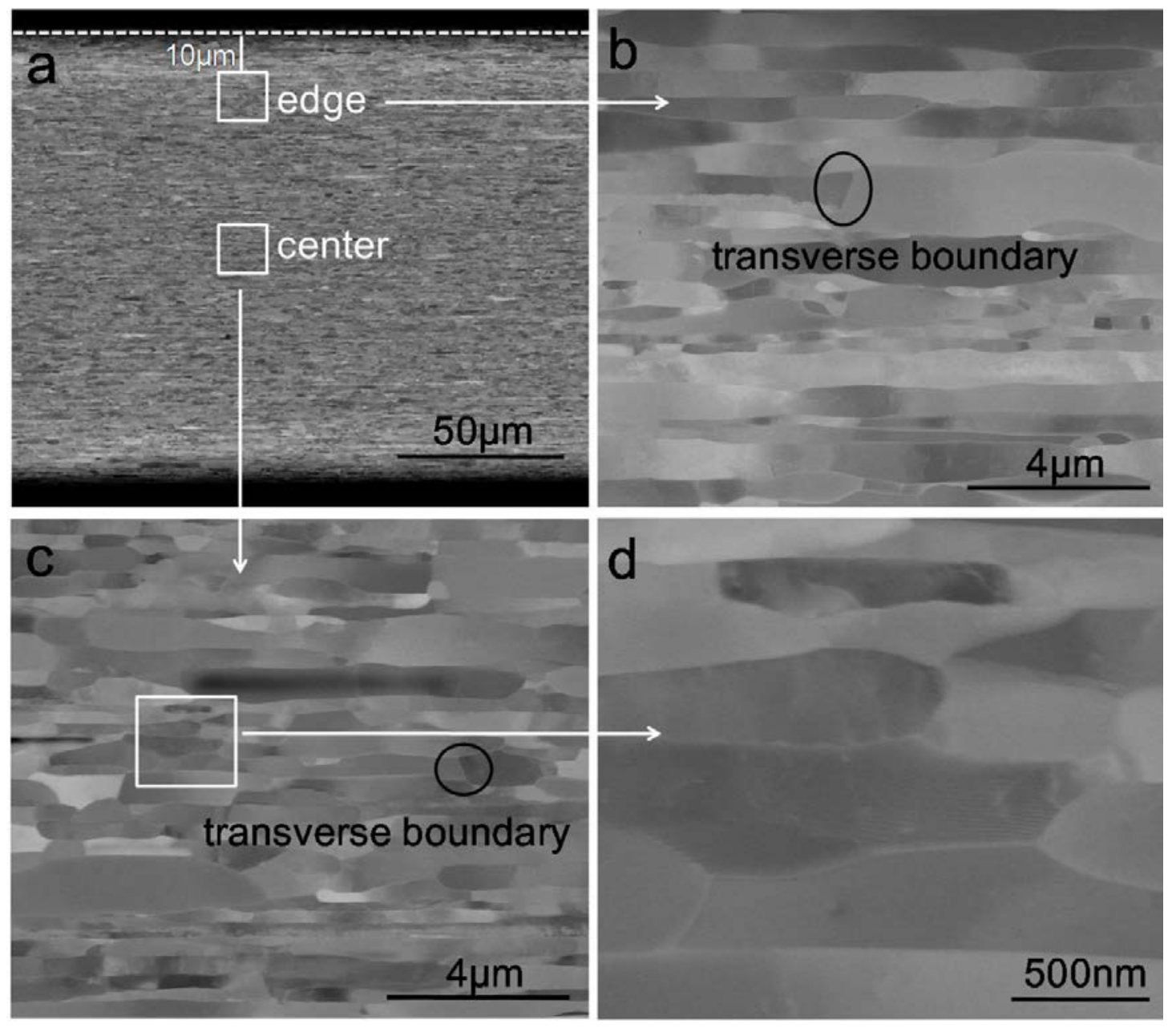

Figure 6. Longitudinal section of the L-heated wire captured by BSE mode in SEM (channelling contrast), including (a) an overview, (b) an image of the edge area, (c) an image of the central area, (d) and a magnified image of the central area.

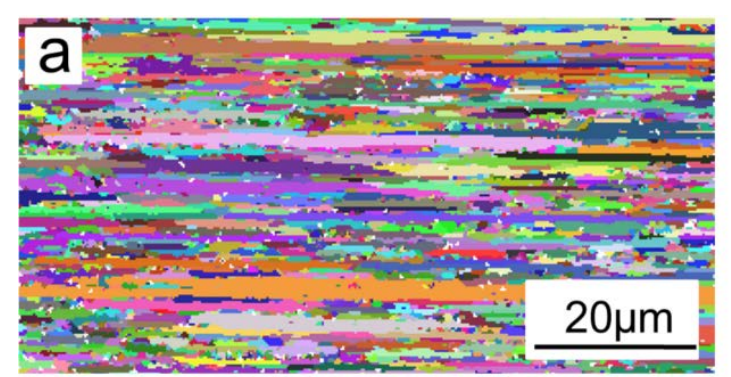

b

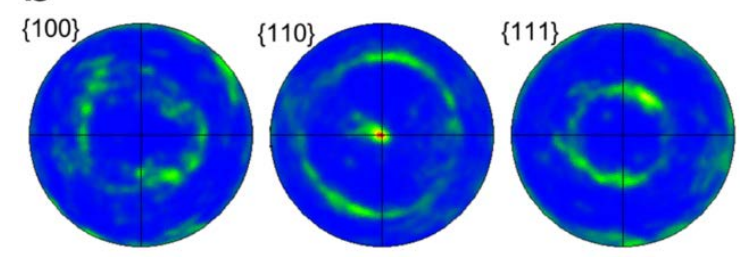

Figure 7. Longitudinal section of the L-heated wire obtained by EBSD: (a) grain map with grains separated from others by boundaries with misorientation angles larger than $10^{\circ}$ shown in arbitrary colours and (b) calculated $\{100\},\{110\}$ and $\{111\}$ pole figures with wire axis in centre. 
Figure 8 shows the cross-section and longitudinal section of the H-heated (1900 K) wire. The grains in both sections are equiaxed but with quite different sizes. The majority of them are small with a size of 5-15 $\mu \mathrm{m}$, between which a few large grains with a size of 30-40 $\mu \mathrm{m}$ are dispersed. Unlike the asfabricated and L-heated samples, the grains are neither fibrous nor elongated. Similar to the L-heated sample they do not show any obvious dislocations. To highlight the grain structure, two different grain maps are provided in Figure 9: one where grains are defined by high angle boundaries with misorientation angles larger than $10^{\circ}$ (Figure 9a), another where subgrains are revealed by low angle boundaries with misorientation angles larger than $2^{\circ}$ (Figure $9 \mathrm{~b}$ ). Obviously, some of the grains with irregular shape in Figure 9a (e.g. the large cyan and green grains) are composed of several subgrains separated by low angle boundaries as shown in the black-bordered boxes in Figure $9 \mathrm{~b}$. The frequently observed speckles consisting of only a few pixels with distinct colour are not considered as real grains, but rather as an artefact resulting from an imperfect surface preparation. The $\mathrm{H}$-heated tungsten wire has a $<110>$ texture as obvious from the $\{110\}$ pole figure in Figure $9 \mathrm{c}$ (the incomplete rings are a result of the limited grain statistics due to the large grain sizes). Consequently, the curled, elongated grains in the as-fabricated wire are replaced by non-curled, non-fibrous ones at $1900 \mathrm{~K}$, while keeping the main grain orientations.
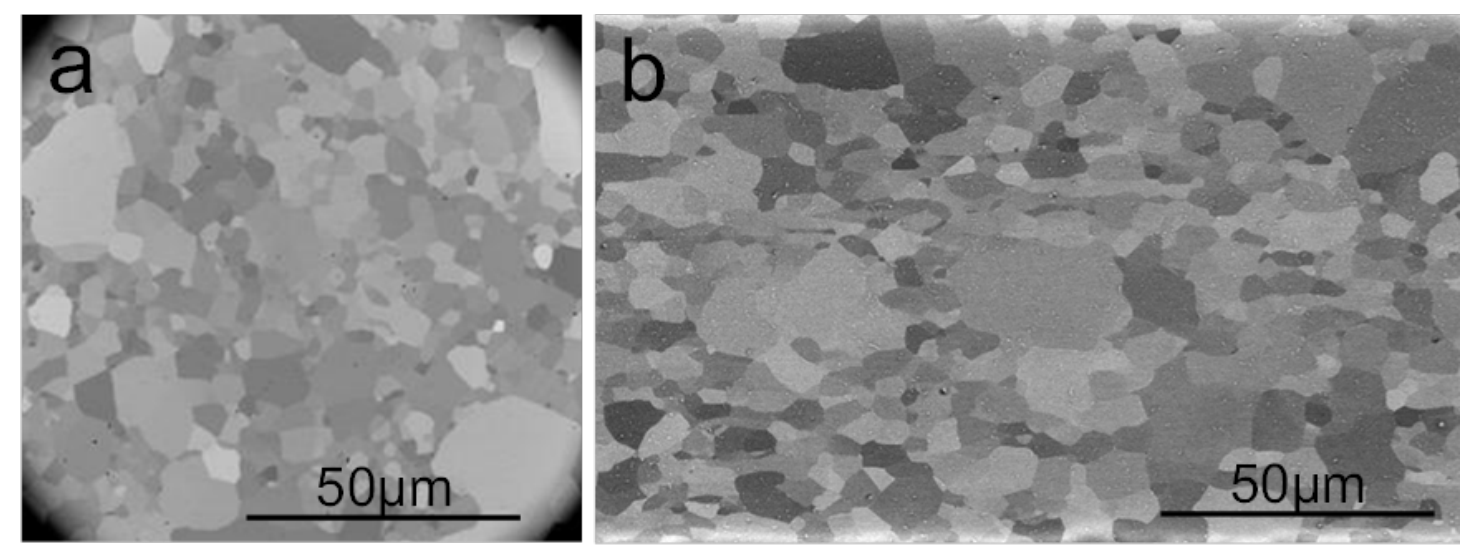

Figure 8. (a) Cross-section and (b) longitudinal section of the H-heated wire captured in BSE mode in SEM (channelling contrast). 

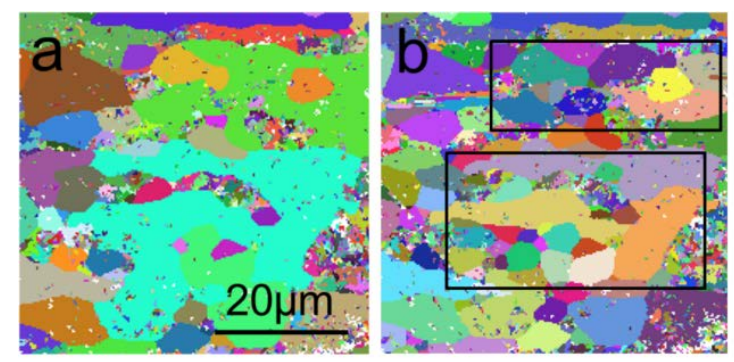

\section{C}

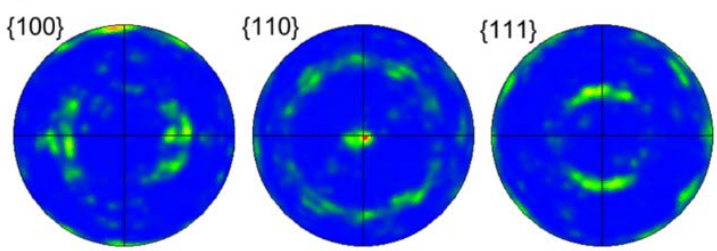

Figure 9. Longitudinal section of the $\mathrm{H}$-heated wire obtained by EBSD: grain maps with (a) grains or (b) subgrains shown in arbitrary colours. Grains and subgrains are defined as continuous areas separated from others by boundaries with misorientation angles larger than (a) $10^{\circ}$ and (b) $2^{\circ}$; (c) calculated $\{100\},\{110\}$ and $\{111\}$ pole figures with wire axis in centre.

From the grain maps obtained by EBSD on the longitudinal sections, the apparent area and the aspect ratio of the individual grains were extracted and analysed statistically. Grains with apparent areas less than $0.5 \mu \mathrm{m}^{2}$ corresponding to less than 8 pixels were considered as artefacts of the measurement or the preparation and excluded from the analysis. Figure 10 represents the corresponding distributions as area weighted fractions after binning on a logarithmic scale. The grain size distributions reveal clearly that the apparent grain size is smallest for the as-fabricated condition, and largest for the $\mathrm{H}$ heated wire. The area weighted geometrical average increases from $4.5 \mu \mathrm{m}^{2}$ over $21 \mu \mathrm{m}^{2}$ to $225 \mu \mathrm{m}^{2}$ for the as-fabricated, L-heated and $\mathrm{H}$-heated condition, respectively. It can also be seen that in the same order the grain size distribution gets more and more skewed towards larger grains. Both the asfabricated and the L-heated wire, show relative high aspect ratios, indicating an elongated grain structure consistent with their fibrous structure observed by SEM. In the L-heated case the aspect ratio is even higher than in the as-fabricated wire, most probably as a consequence of the vanished curling and the full alignment of the grains to the wire axis. In contrast to that, the grains in the H-heated wire have relatively small aspect ratios and the majority of the grains have an aspect ratio smaller than 4 . 

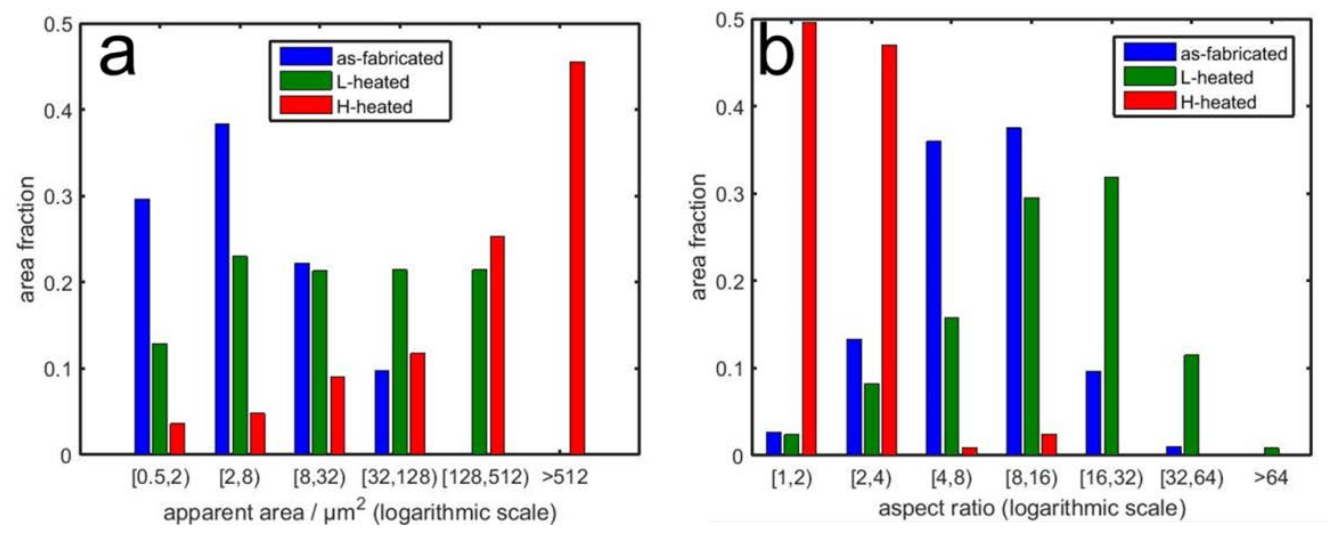

Figure 10. Distributions of (a) the apparent grain area and (b) the aspect ratio of grains detected in the longitudinal sections of the as-fabricated, L-heated and $\mathrm{H}$-heated wires by EBSD. Only grains with a minimum area of $0.5 \mu \mathrm{m}^{2}$ corresponding to 8 pixels are considered. The data are binned in a logarithmic manner and the area fraction occupied by the individual fractions is presented.

\subsection{Mechanical behaviour}

\subsubsection{Stress-strain curves and energy absorption}

Typical engineering stress - engineering strain curves of the differently treated tungsten wires are shown in Figure 11. Five curves are shown for both as-fabricated and L-heated heated samples and one for $\mathrm{H}$-heated samples. For as-fabricated and L-heated samples solid lines and closed symbols are used where the rupture happens within the gauge length. For these samples the necking behaviour is reflected in the curves. The $\mathrm{H}$-heated samples always failed before yielding with a failure stress ranging widely, between $235 \mathrm{MPa}$ to $1137 \mathrm{MPa}$, thus only the curve of one sample with an intermediate failure stress is shown.

Evaluation of the Young's modulus results in a value of $406 \pm 13 \mathrm{GPa}$, which is in the range of reported values for tungsten (400-411 GPa) [25]. All the errors reported here and in the following are calculated as standard deviations of the mean. The H-heated samples do not show any plastic deformation, whereas the as-fabricated and L-heated samples both undergo elastic and plastic deformation. The asfabricated samples show a remarkable work-hardening, increasing the flow stress by $50 \%$ for a strain of $2 \%$, while the L-heated samples show only a marginal increase of the flow stress with strain with a much lower work hardening rate, i.e. a much smaller slope of the engineering stress - engineering strain curve due to plastic deformation. The yield strength was defined by an offset yield point at a strain of $0.0002(0.02 \%)^{2}$. The yield strength $\left(R_{\mathrm{p} 0.02}\right)$ is determined to be $1991 \pm 34 \mathrm{MPa}$ and $1689 \pm 4 \mathrm{MPa}$ for the as-fabricated and L-heated wires, respectively.

\footnotetext{
${ }^{2}$ In contrast to the standard value of $0.002(0.2 \%)$ an offset of $0.0002(0.02 \%)$ avoids incorporation of any significant plastic deformation in the case of the here tested samples.
} 
The energy consumed by plastic deformation was analysed and the results are summarized in table 1 . The region before yielding represents the elastically stored energy density. The uniform plastic deformation and the necking regime are separated by the maximum load, which is usually defined as the starting point of necking [26]. The plastic work up to the onset of necking is homogeneously distributed along the whole sample and is therefore determined by integrating the area under the stress-strain curve. In this manner, the values reported allow comparison of samples with different gauge lengths. On the other hand, the gauge length becomes relevant for necking (and the necking energy) as the deformation occurs localized in the neck. In this case, it is better to compare actual energies (or work) which can either be obtained by multiplying obtained energy densities by the volume or directly by integrating the force-displacement curve. The results for the uniform plastic work density are based on five measurements for each kind of treatment, while the necking energy is based on the two measurements (solid lines in Figure 11) which include the necking behaviour. Both the asfabricated and L-heated wires require comparable work for the necking. The H-heated wire showed no plastic deformation and is therefore not shown in table 1.

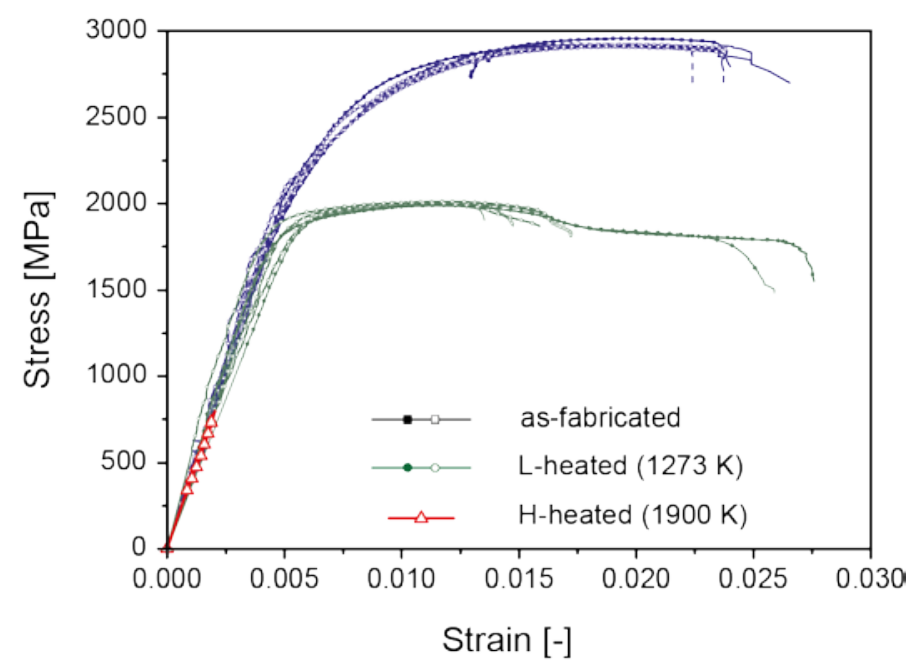

Figure 11. Engineering stress - engineering strain curves of five as-fabricated, five L-heated and one $\mathrm{H}$-heated wire samples pulled at a speed of $5 \mu \mathrm{m} / \mathrm{s}$. Solid lines and filled symbols represent samples which failed within the gauge length, dotted lines and open symbols samples which failed outside the gauge length respectively.

Table 1. Energy absorption of the as-fabricated and L-heated wires before failure in tensile testing.

\begin{tabular}{cccc}
\hline & $\begin{array}{c}\text { Elastic energy } \\
\text { density } \\
{\left[\mathrm{mJ} / \mathrm{mm}^{3}\right]}\end{array}$ & Uniform plastic work density & Necking energy \\
\hline As-fabricated & $5.2 \pm 0.2$ & $38.3 \pm 0.5$ & {$[\mathrm{~mJ}]$} \\
\hline L-heated & $4.0 \pm 0.3$ & $13.1 \pm 0.5$ & $5.8 \pm 0.5$ \\
\hline
\end{tabular}




\subsubsection{Ultimate tensile strength}

The ultimate tensile strength was evaluated based on a Weibull distribution. The Weibull modulus, the shape parameter of the Weibull distribution, is normally used to describe variability in measured strength and can indicate the ductility or brittleness of a material [27-29]. For brittle materials, brittle failure initiates from flaws distributed in the material and vary from specimen to specimen [30]. In this case the measured strength becomes broadly distributed, the Weibull modulus is determined to be low, and the strength is better expressed as a distribution. Therefore, a small Weibull modulus is a feature of brittle materials. Accordingly, a high Weibull modulus indicates a ductile state of a material and a single value can be used as a description of the strength. The Weibull modulus $k$ and the scale parameter $\lambda$ for the ultimate tensile strength of the respective Weibull distribution of tungsten wires have been evaluated using Bayesian parameter estimation [31]. The posterior distribution $p(\lambda, k /$ data, $I)$, which describes the joint probability distribution of $\lambda$ and $k$ in the light of the measured data can be calculated using Bayes' theorem as shown in equation (1), where $p(\lambda, k / I)$ denotes the prior knowledge about the parameters and $p($ data $\mid \lambda, k, l)$ is the probability distribution of the measured data, i.e. the likelihood, which, in the present case, is given by the Weibull distribution: equation (2), with $d_{i}$, $i=1, \ldots, N$ denoting the $N$ measured data points. From this joint probability distribution the probability distributions for $\lambda$ and $k$ individually can be obtained by marginalisation of the respective other parameter [32]. As prior distribution a flat (uniform) distribution for positive parameter values of $\lambda$ and $k$ was applied. The probability density for negative parameter values was set to zero (matching the definition of the Weibull distribution). This choice also yields the special case of the maximumlikelihood estimate as mode of the posterior density. Eventually the parameter means were estimated using unbiased rejection Monte Carlo sampling [33,34] from the posterior distribution.

$$
\begin{aligned}
& p(\lambda, k \mid \text { data }, I)=\frac{p(\text { data } \mid \lambda, k, I) p(\lambda, k \mid I)}{p(\text { data } \mid I)} \\
& p(\text { data } \mid \lambda, k, I)=\prod \frac{k}{\lambda}\left(\frac{d_{i}}{\lambda}\right)^{k-1} \mathrm{e}^{-\left(d_{i} / \lambda\right)^{k}}
\end{aligned}
$$

The calculated Weibull moduli and scale parameters for the ultimate tensile strength are shown in table 2. The results of the as-fabricated, L-heated and H-heated wires are based on 50, 12 and 33 samples, respectively. The measured strength values and the Weibull distributions are plotted in Figure 12. The measured ultimate tensile strengths of the as-fabricated and L-heated samples are in a very narrow range of 2914-2940 MPa and 1936-1996 MPa, respectively. Accordingly, their Weibull modulus is high (about 200). Hence, the specific values, $2926 \mathrm{MPa}$ for as-fabricated and $1983 \mathrm{MPa}$ for L-heated wires which are the points showing the highest probability density of failure in the Weibull distribution, can be used to express their ultimate tensile strength. The strength of the L-heated wire is lower than that of the as-fabricated wire. In contrast, the measured strength of the $\mathrm{H}$-heated wire varies over a wide range from $235 \mathrm{MPa}$ to $1137 \mathrm{MPa}$. Consequently, the Weibull modulus is relatively small (around 
3.45) and the strength cannot be represented by a single value, but only by the entire Weibull distribution.

Table 2. Weibull modulus and scale parameter of Weibull distributions for the ultimate tensile strengths of as-fabricated, L-heated and $\mathrm{H}$-heated wires

\begin{tabular}{cccc}
\hline & as-fabricated & L-heated & H-heated \\
\hline Weibull modulus & $211.8 \pm 18.0$ & $177.0 \pm 30.0$ & $3.45 \pm 0.37$ \\
Scale parameter [MPa] & $2926.0 \pm 1.5$ & $1983.0 \pm 2.6$ & $896.6 \pm 33.6$ \\
\hline
\end{tabular}

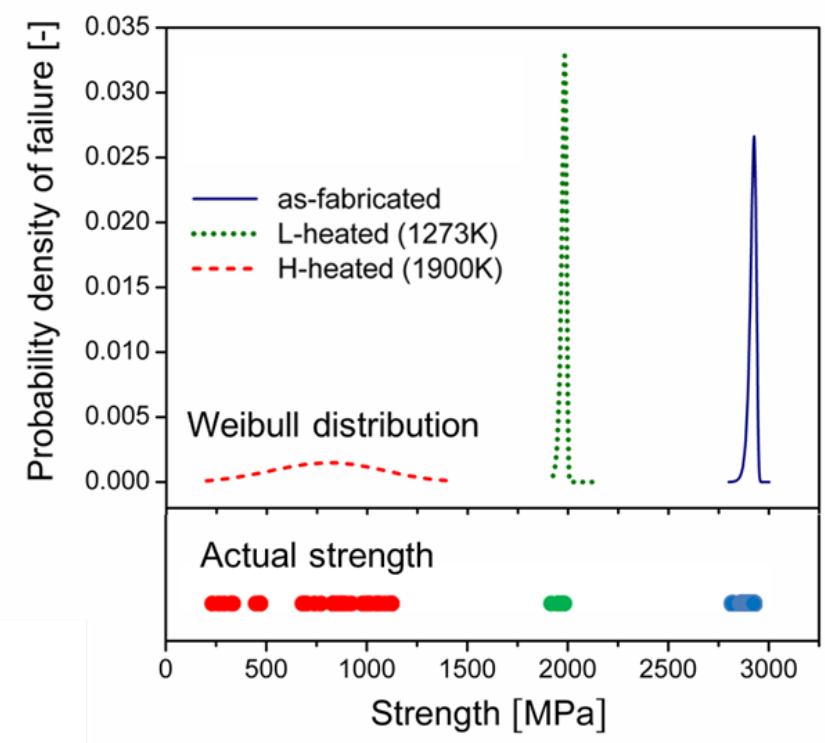

Figure 12. Weibull distributions and measured ultimate tensile strengths of the as-fabricated, Lheated and $\mathrm{H}$-heated wires pulled at a speed of $5 \mu \mathrm{m} / \mathrm{s}$.

\subsubsection{Geometry of necking zones}

The necking geometry was evaluated from the 3D data obtained by CLSM measurements. Figure 13a and 13b show typical necking zones for the as-fabricated and L-heated wires, where different colours indicate different heights. The H-heated wire did not show any necking and is therefore not shown. Only one half of the fractured sample is shown. Although the two halves are not exactly symmetric and the length of the necking zones varies by about $10 \%$, this provides a good idea of the necking profile. The height profile was adjusted in a way that the undeformed surface of the wire (far from the neck) is parallel to the $x$-axis (wire axis) and the height is set to zero. By this, any influence of the way of mounting is avoided. The measurements revealed an axis-symmetry of the deformation in the necking zone. Enabled by this axis-symmetry, the contour of deformation is evaluated by extracting the highest point of each pixel row parallel to the wire axis. These values are shown in Figure $13 \mathrm{c}$ versus the $x$ coordinate. In this case, the average of the 12 highest points was used to reduce signal noise. The beginning of the necking zone (indicated by the coloured dashed lines in Figure $13 \mathrm{c}$ ) is defined as the point where the radius deviates by more than one percent from the initial fibre radius, i.e., $0.75 \mu \mathrm{m}$. 
These points mark the length of one half of the necking zone and together with the corresponding other half, the necking length is determined. The reduction in the diameter is calculated using the radius at the fracture surface $(x=0)$.

The length of the necking zone and the reduced area were determined for five as-fabricated and Lheated samples each. The length of the necking zones of the wires were $253 \pm 3 \mu \mathrm{m}$ (as-fabricated) and $440 \pm 8 \mu \mathrm{m}$ (L-heated), respectively. The percentage reduction of the cross-sectional area was around $40 \%$ (as-fabricated) and $50 \%$ (L-heated), respectively. Necking in the L-heated wire is more pronounced with a wider necking zone and a higher area reduction. Assuming volume conservation during the test, the initial length of the necking zone can be calculated. The volume after the test is calculated using the radii along the wire axis (Figure 13c) similar to the procedure described in [14]. Assuming a cylindrical volume before the test, the initial lengths of the necking zones were calculated to be $207 \pm 3 \mu \mathrm{m}$ and $356 \pm 6 \mu \mathrm{m}$ for the as-fabricated and L-heated samples, respectively. Consequently, the elongation of the necking zones, necking length minus original length, become $46 \pm 4 \mu \mathrm{m}$ and $84 \pm 10$ $\mu \mathrm{m}$, respectively, reflecting again the more pronounced necking behaviour of the L-heated specimens.
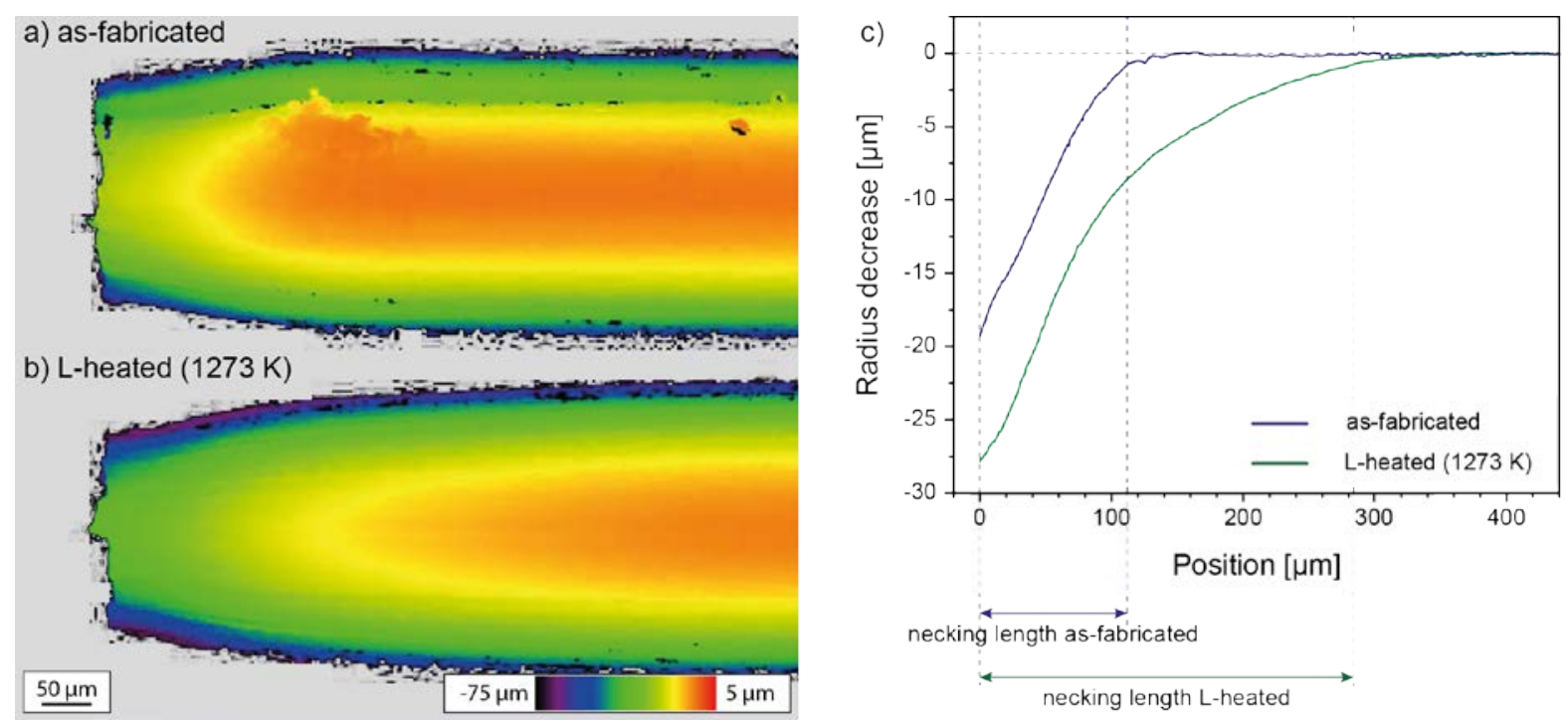

Figure 13. Height distributions of the necking zones of (a) an as-fabricated and ( $b$ ) an L-heated sample obtained by CLSM and (c) measured height decrease (corresponding to a radius reduction) along the wire axis.

\subsection{Fracture modes}

The fracture surface of the as-fabricated wire shown in Figure 14a reveals longitudinal cracks (often referred to as splits if occurring in drawn wires) and convoluted ribbons. The cracks seem to originate at the ribbons and they are facing towards the wire centre. They tend to be wider at the fibre surface. Figure $14 \mathrm{c}$ with higher magnification indicates that the cracks are due to longitudinal grain delamination along grain boundaries; within the ribbons, necking of individual grains to almost $100 \%$ 
reduction in area (termed knife-edge-necking of individual grains here) occurs. The outside of the fibre near the fracture zone (Figure 14b) is rough due to axial and transverse marks. Overall, the asfabricated wire involved a combination of two fracture modes: longitudinal cracks and knife-edgenecking of individual grains.

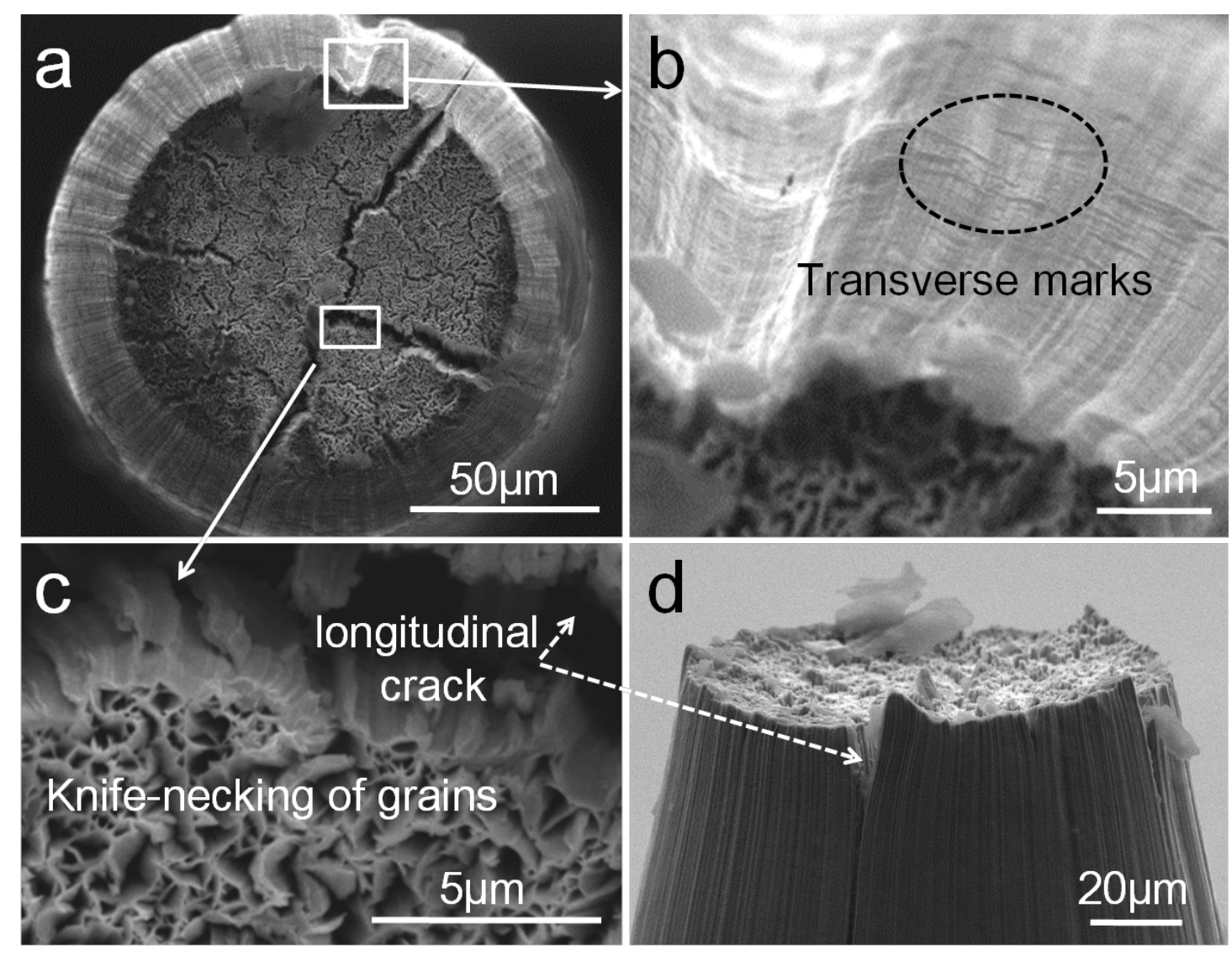

Figure 14. (a) Top view of fracture surface of an as-fabricated wire pulled to failure at a speed of 5 $\mu \mathrm{m} / \mathrm{s}$, with magnified details showing (b) the outside of the wire and (c) the knife-necking of individual grains, as well as (d) the side view showing a large longitudinal crack often referred to as split if occurring in drawn wires.

The failure appearance of the L-heated wire is shown in Figure 15. It includes longitudinal cracks, cleavage and knife-edge-necking of individual grains, where cleavage dominates at the wire edge, while knife-edge-necking of grains dominates in the centre of the wire. The cleavage surface is roughly perpendicular to the wire axis (Figure 15b and 15c) and, as a consequence of the $<110>$ fibre texture, along $\{110\}$ planes. The outside of the fibre is rough, similar to the as-fabricated case. 

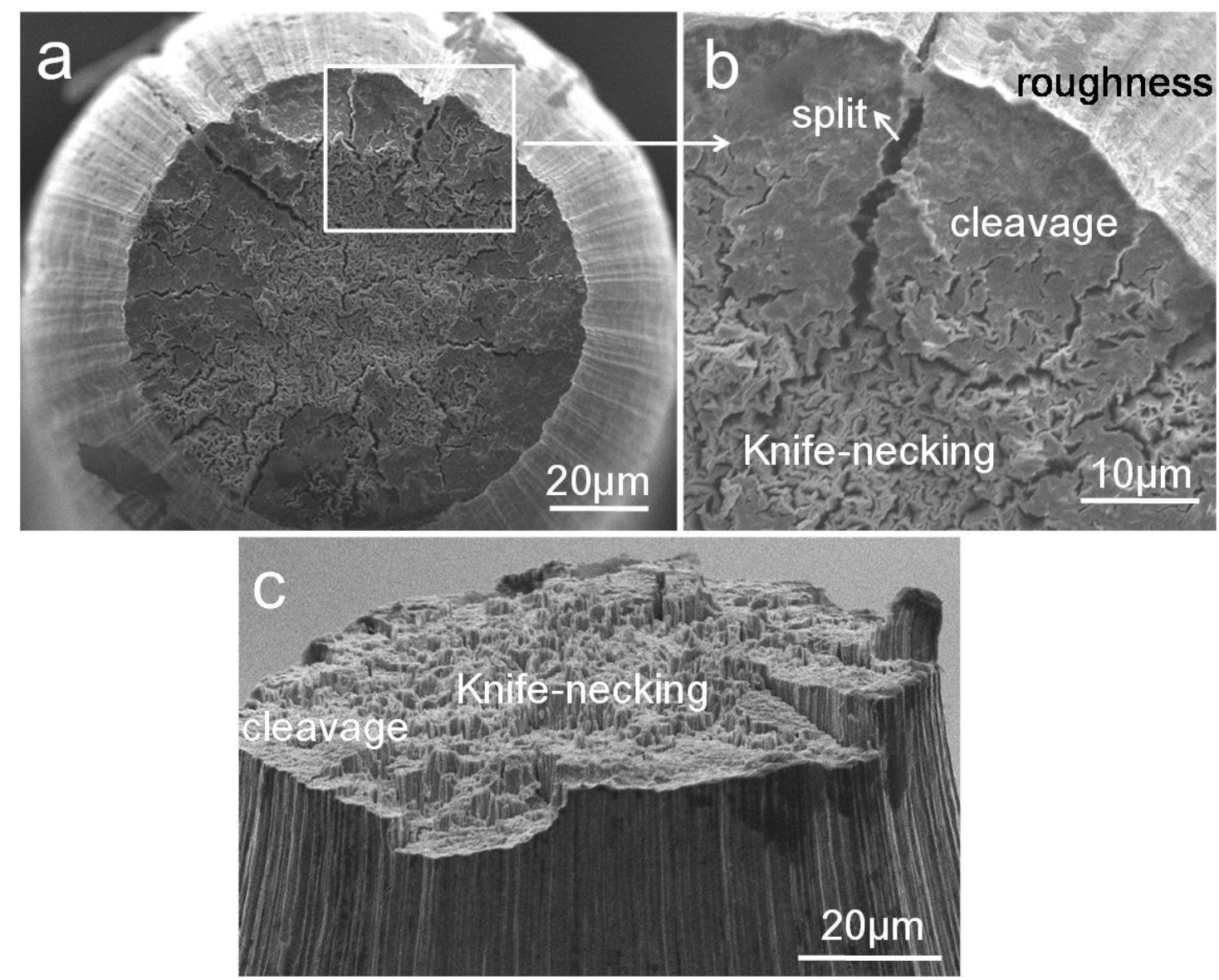

Figure 15. (a) Fracture surface, (b) detailed structure of cleavage and knife-edge-necking, and (c) side view of the L-heated wire pulled at a speed of $5 \mu \mathrm{m} / \mathrm{s}$.

The failure of the $\mathrm{H}$-heated wire is composed of two mechanisms: cleavage and intergranular fracture, characterized as brittle fracture (Figure 16). The cleavage surface is at an angle of about $45^{\circ}$ to the wire axis.
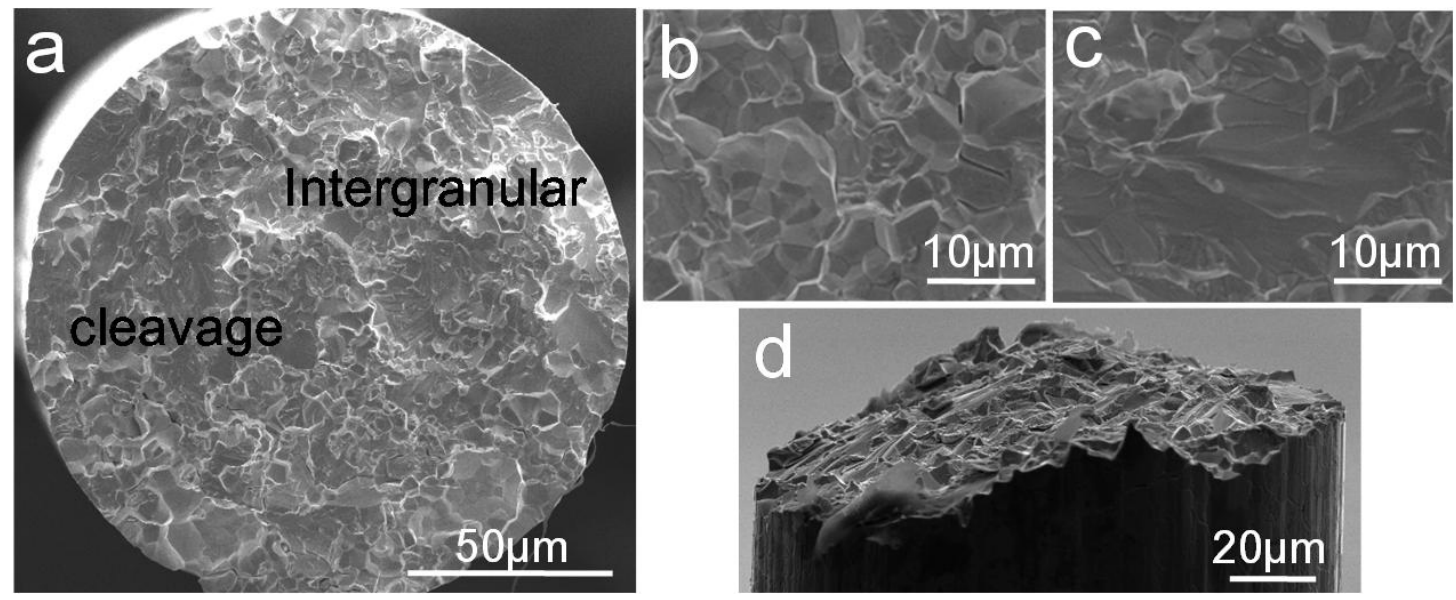

Figure 16. (a) Fracture surface, detailed structure of (b) intergranular fracture, (c) cleavage, and (d) side view of the $\mathrm{H}$-heated wire pulled at a speed of $5 \mu \mathrm{m} / \mathrm{s}$.

\section{Discussion}




\subsection{Microstructural evolution}

The as-fabricated fibres show an elongated and curled grain structure which is typical for drawn tungsten wire [20, 35]. During the drawing process, tungsten wire undergoes severe plastic deformation, the grains develop an elongated shape and a $\langle 110\rangle$ fibre texture is formed. The preference of plane strain elongation of individual grains leads to grain curling, the so called Hosford structure [24]. The grains are relatively small and have a rather high aspect ratio. However, as mentioned before, the length of the grains and thus the aspect ratio is probably underestimated as some grains might be bent out of the plane of observation due to the curling.

The low-temperature heat treatment caused a transformation from this structure with curled grains in the as-fabricated wire to a new, non-curled structure consisting of long grains with an equiaxed cross-section. The grain size actually increased compared to the as-fabricated wire, but the grains remain clearly elongated (the high aspect ratio is conserved, even increased). Recrystallization is usually defined as a process which occurs when a deformed structure develops into a new grain structure through nucleation and by motion of high-angle boundaries driven by the stored energy of deformation [36]. Therefore, the change in morphology is regarded as an indication that recrystallization has indeed happened during low-temperature annealing at $1273 \mathrm{~K}$. Further evidence is gained from the complete removal of dislocation structures in Figure $6 \mathrm{~d}$ compared to Figure $3 \mathrm{~d}$. The severe plastic deformation during wire drawing leads to a high dislocation density and an abundant stored energy after the deformation. This reduces the recrystallization temperature because of a higher driving force from possible energy release as well as a higher nucleation rate due to the abundance of defects [36]. Therefore, the drawn wire undergoes recrystallization during 3 hours at $1273 \mathrm{~K}$ which is a much lower temperature than the normally reported recrystallization temperature of tungsten (1523 K-1773 K) [37-39].

During the heat treatment at $1900 \mathrm{~K}$ the fibrous grains recrystallize and form (after possibly subsequent grain growth) large, equiaxed shaped grains. This is accompanied by the removal of stored dislocations, low angle boundaries and subgrains as well as the majority of high angle boundaries $[25,27]$. The texture remains essentially unaltered during heat treatment at both temperatures, but this cannot be taken as evidence for the absence of recrystallization.

\subsection{Mechanical behaviour}

The mechanical behaviour of both as-fabricated and L-heated wires, as revealed from their stressstrain curves, displays significant plastic deformation and high energy dissipation after yielding, a relatively high Weibull modulus of about 200 for the distribution of the ultimate tensile strength and similar necking shapes, all indicating their ductile behaviour. The $\mathrm{H}$-heated wire shows no plastic deformation at all, neglibible energy dissipation, and a relatively small Weibull modulus of 3.45, indicating its brittleness. The as-fabricated wire exhibits a higher yield stress and ultimate tensile 
strength, while the necking of L-heated wire is more pronounced. The curling structure in the asfabricated wire seems to be beneficial for interlocking the grain boundaries and reducing grain boundary sliding, leading to high yield strength. The high density of dislocations in the severely deformed condition is seen as the major reason for the high work-hardening rate, suppressing premature necking and leading to a high tensile strength. The heat treatment at $1273 \mathrm{~K}$ causes stress relief and recrystallization leading to coarser grains and a reduction of the dislocation density in the Lheated wire. Under these circumstances, the dislocations are less likely to be blocked in their motion by other dislocations, leading to a higher mean free path, resulting not only in lower yield strength, but also in a lower work-hardening rate (as obvious from the small slope in the engineering stress engineering strain curve) and an earlier onset of a more pronounced necking.

It is important to emphasize that the L-heated wire recrystallized at $1273 \mathrm{~K}$ is not embrittled by recrystallization as normally reported for tungsten [12]. Only the $\mathrm{H}$-heated wire, recrystallized at $1900 \mathrm{~K}$ and therefore having lost the elongated grain structure, shows brittle behaviour. Referring to the discussion of the microstructure in section 4.1, one may conclude that the fine elongated grains with high aspect ratio play the most important role in the ductility of tungsten wire. In the finer grain structure, plastic deformation in adjacent grains is coupled and the risk of stress concentration is reduced. Due to the high aspect ratio and the long extension along the wire axis, only a low number of transversal grain boundaries subjected to the risk of being perpendicular to the main tensile load exist. Even if such a small transverse grain boundary delaminates, the growth of the crack will be impeded by adjacent axial grain boundaries and no brittle fracture of the entire cross-section will occur, similar to the mechanism of fibre-reinforced composites $[40,41]$ and also proposed for $W$ wire before [14]. Although tensile tests on single crystal tungsten with various orientations lead to the conclusion that $<110>$ oriented samples show the highest total strain [42], texture does not seem to play any role in the case presented here: all wires show a similar $\{110\}$ fibre texture; nevertheless, $\mathrm{H}$-heated samples did not show any sign of ductility.

\subsection{Fracture modes}

The fracture surfaces of the as-fabricated and L-heated samples show some common features: longitudinal cracks and knife-edge-necking of individual grains. The longitudinal cracks are driven by circumferential stresses caused by the drawing of the wire $[43,44]$. As the maximum circumferential stress occurs at the surface this explains also why the cracks originate at the surface. The transverse marks (see Figure 14b) observed also on $<110>$ oriented tungsten single crystals, are inferred to be slip traces corresponding to (110)[110] type slip [42]. Knife-edge-necking of individual grains, similar to the knife-edge fracture observed in a $<110>$ tungsten single crystal, results from their intrinsic plane strain elongation [20], which is a consequence of the $<110>$ fibre texture and the main reason for curling.

Beyond that, the fracture surface of the L-heated samples includes cleavage at the edge. The reason why cleavage happens at the edge of the wire and not in the centre is proposed to be the heterogeneity 
of the stress state across the wire diameter. The axial stresses within the neck are shown in Figure 17a with highest axial stresses in the interior [45]. Additionally, longitudinal cracks at the edge can cause stress relief. In summary, the edge region experiences lower axial and lower hydrostatic stresses. It is inferred that at the edge part, the slip systems responsible for plane strain elongation and accounting for the knife-edge-necking of grains are less likely to be activated due to the lower stresses present. Therefore, higher stresses are considered to be beneficial for knife-edge-necking of grains. This proposed explanation is supported by the fracture behaviour of the L-heated wire subjected to a tensile test with a very high speed of $5 \times 10^{3} \mu \mathrm{m} / \mathrm{s}$. The tensile strength of $2337 \mathrm{MPa}$ is significantly higher than that of the sample pulled at a speed of $5 \mu \mathrm{m} / \mathrm{s}(1983 \mathrm{MPa})$, and the knife-edge-necking of individual grains dominates all over the fracture surface shown in Figure 17b.

The $\mathrm{H}$-heated wire cracks in a typical brittle manner, showing both cleavage and intergranular failure. Based on the preliminary results (three samples), the cleavage seems to occur at angles of about $45^{\circ}$ with the wire axis. $\{100\}$ planes are very likely to be the main cleavage plane of the recrystallized, brittle tungsten wire. All features of the microstructure (non-fibrous), mechanical behaviour and failure mode of tungsten wires heated to high enough temperatures ( $1900 \mathrm{~K}$ in this study) are similar to the ones reported for conventional tungsten materials [46-48].
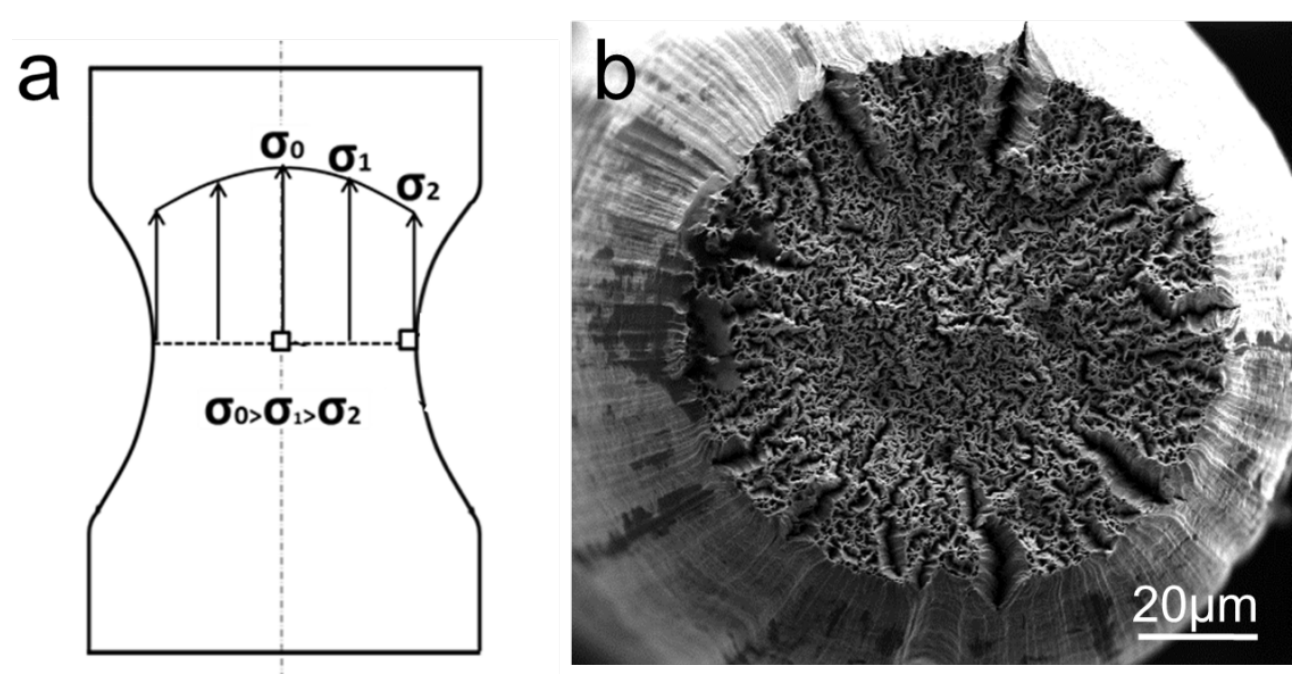

Figure 17. (a) Axial stress in the central necking zone (according to [45] adapted from [49]) and (b) the fracture surface of the L-heated tungsten wire pulled at a speed of $5 \times 10^{3} \mu \mathrm{m} / \mathrm{s}$.

\subsection{Consequence for $W_{f} / W$}

In $\mathrm{W}_{\mathrm{f}} / \mathrm{W}$ composites the energy consumed by plastic deformation of the tungsten wire used as fibres was shown to play a significant role for their toughness [6]. As shown above, wire heated up to a temperature of $1273 \mathrm{~K}$ still shows plastic deformation and could therefore still contribute to this effect. In contrast to that, wire heated up to $1900 \mathrm{~K}$ does not show any plastic deformation. Composites heated up to this temperature would therefore lose any contribution to toughening by fibre ductility. 
In potassium doped tungsten wire, the temperature for losing ductility is significantly increased while showing similar deformation behaviour [13]. The use of doped wire offers therefore an easy way to increase the allowed operation temperature [50].

Within a composite, the wire is constrained by the adhesion to the matrix which plays a significant role in the development of the deformation. Tension tests have been conducted on $W_{f} / W$ single composites (a single tungsten fibre surrounded by a tungsten matrix) with fibres similar to the wires investigated here [6]. These samples subjected to a stepwise tension test at a displacement speed of $0.1 \mu \mathrm{m} / \mathrm{s}$, show a debonded region of $66 \mu \mathrm{m}$ experiencing necking and an overall elongation of $90 \mu \mathrm{m}$. The debonding length of $66 \mu \mathrm{m}$ is only several times the typical grain length of the wire $(10-40 \mu \mathrm{m})$ and much shorter than the initial length of the necking zone of the free wire determined here (220 $\mu \mathrm{m})$. However, the elongation of $90 \mu \mathrm{m}$ is higher than that of the necking zone of the free wire in the as-fabricated condition $(47 \mu \mathrm{m})$. The difference is probably mainly caused by the differences in the free length and therefore the constraint due to adhesion. However, influences of the low tensile speed and the step wise character of the test cannot be excluded.

\section{Conclusion}

Pure tungsten wire used as fibres in tungsten fibre-reinforced composites has been investigated by means of tension tests in the as-fabricated case and after annealing at $1273 \mathrm{~K}$ and $1900 \mathrm{~K}$. The wire shows recrystallization for both annealing temperatures. As-fabricated (drawn) wire and wire recrystallized at $1273 \mathrm{~K}$ both exhibit a fibrous structure of fine grains with a high aspect ratio and similar ductile mechanical and fracture behaviour. For wire samples recrystallized at $1900 \mathrm{~K}$, the non-fibrous grain structure and the concomitant brittle properties are similar to the ones reported for conventional tungsten materials. The ductility of this wire can therefore contribute to the toughness in $W_{f} / W$ composites up to a temperature of at least $1273 \mathrm{~K}$.

The main conclusion of this work is that recrystallization in tungsten wire does not necessarily result in embrittlement as it is the case in bulk tungsten. The fibrous grain shape, i.e., a high aspect ratio, is seen as the key parameter for the ductility of tungsten wire. Investigations at additional temperatures could allow more insight into the recrystallization process and the role of the loss of an elongated grain structure.

\section{Acknowledgements}

The authors wish to thank G. Matern and S. Elgeti for their assistance in microscopy and A. Eadie for proofreading. We thank S. Wurster of the Erich-Schmid-Institute in Leoben for performing the high temperature heat treatment. This work has been carried out within the framework of the EUROfusion Consortium and has received funding from the Euratom research and training programme 2014-2018 
under grant agreement No 633053. The views and opinions expressed herein do not necessarily reflect those of the European Commission.

\section{References}

[1] J.W. Coenen, S. Antusch, M. Aumann, W. Biel, J. Du, J. Engels, S. Heuer, A. Houben, T. Höschen, B. Jasper, F. Koch, A. Litnovsky, Y. Mao, R. Neu, G. Pintsuk, J. Riesch, M. Rasinski, J. Reiser, M. Rieth, B. Unterberg, T. Weber, T. Wegener, J.-H. You, C. Linsmeier, Materials for DEMO and reactor applications-boundary condition and new concepts, Phys. Scripta T167 (2016) 014002.

[2] G. Pintsuk, Tungsten as a plasma-facing material, Comprehensive Nucl. Mater. 4 (2012) 551581.

[3] J. Du, T. Hoeschen, M. Rasinski, J.-H. You, Interfacial fracture behavior of tungsten wire/ tungsten matrix composites with copper-coated interface, Mater. Sci. Eng. A 527 (2010) 16231629.

[4] J. Du, T. Hoeschen, M. Rasinski, J.-H. You, Shear debonding behavior of a carbon-coated interface in a tungsten fiber-reinforced tungsten matrix composite, J. Nucl. Mater. 417 (2011) 472-476.

[5] J. Riesch, T. Höschen, C. Linsmeier, S. Wurster, J.-H. You, Enhanced toughness and stable crack propagation in a novel tungsten fibre-reinforced tungsten composite produced by chemical vapour infiltration, Phys. Scripta T159 (2014) 014031.

[6] J. Riesch, J.Y. Buffiere, T. Hoeschen, M. di Michiel, M. Scheel, C. Linsmeier, J.-H.You, In situ synchrotron tomography estimation of toughening effect by semi-ductile fibre reinforcement in a tungsten-fibre-reinforced tungsten composite, Acta Mater. 61 (2013) 7060-7071.

[7] R. Neu, J. Riesch, J. Coenen, J. Brinkmann, A. Calvo, S. Elgeti, C. Garcia-Rosales, H. Greuner, T. Höschen, G. Holzner, F. Klein, F. Koch, C. Linsmeier, A. Litnovsky, T. Wegener, S. Wurster, J.-H. You, Advanced tungsten materials for plasma-facing components of DEMO and fusion power plants, Fusion Eng. Des. 109 (2016) 1046-1052.

[8] J.W. Coenen, J. Riesch, J.-H.You, Advanced materials for a damage resilient divertor concept for DEMO, 29th Symposium on Fusion Technology, 2016.

[9] I.W. Donald, P.W. Mcmillan, Ceramic-matrix composites, J. Mater. Sci. 11 (1976) 949-972.

[10]D.B. Marshall, A.G. Evans, Failure mechanisms in ceramic-fiber/ceramic-matrix composites, J. Am. Ceram. Soc. 68 (1985) 225-231.

[11]W.A. Curtin, Theory of mechanical properties of ceramic-matrix composites, J. Am. Ceram. Soc. 74 (1991) 2837-2845.

[12]E. Pink, L. Bartha, The metallurgy of doped/non-sag tungsten, Springer, 1989, pp. 75-79; 109111.

[13]J. Riesch, Y. Han, J. Almanstötter, J.W. Coenen, T. Höoschen, B. Jasper, P. Zhao, C. Linsmeier, R. Neu, Development of tungsten fibre-reinforced tungsten composites towards their use in DEMO-potassium doped tungsten wire, Phys. Scripta T167 (2016) 014006.

[14]J. Riesch, J. Almanstötter, J.W. Coenen, M. Fuhr, H. Gietl, Y. Han, T. Höschen, C. Linsmeier, N. Travitzky, P. Zhao, R. Neu, Properties of drawn W wire used as high performance fibre in 
tungsten fibre-reinforced tungsten composite, IOP Conf. Series: Materials Science and Engineering 139 (2016) 012043.

[15]S. Guo, G. He, G. Liu, Z. Yang, J. Li, Interfacial failure mechanism in tungsten fiber reinforced copper-based composites fabricated by combustion synthesis melt infiltration under ultrahigh gravity, Mater. Des. 87 (2015) 901-904.

[16]Z. Wu, G.H. Wu, P.C. Kang, Q. Gou, G.Q. Chen, L.T. Jiang, High temperature fracture behavior of tungsten fiber reinforced copper matrix composites under dynamic compression, Mater. Des. 32 (2011) 5022-5026.

[17]B.P. Wang, B.Q. Yu, Q.B. Fan, J.Y. Liang, L. Wang, Y.F. Xue, H.F. Zhang, H.M. Fu, Anisotropic dynamic mechanical response of tungsten fiber/Zr-based bulk metallic glass composites, Mater. Des. 93 (2016) 485-493.

[18]L. Ma, L. Zhang, P. Zhao, N. Hu, Z. Gong, W. Ye, A new design of composites for thermal management: Aluminium reinforced with continuous CVD diamond coated W spiral wires, Mater. Des. 101 (2016) 109-116.

[19]J.-H. You, I. Komarova, Probabilistic failure analysis of a water-cooled tungsten divertor: Impact of embrittlement, J. Nucl. Mater. 375 (2008) 283-289.

[20]S. Leber, J. Tavernelli, D.D. White, Fracture modes in tungsten wire, J. Less Common Met. 48 (1976) 119-133.

[21]D.B. Snow, The recrystallization of heavily-drawn doped tungsten wire, Metall. Trans. A 7A (1976) 783-794.

[22]http://imagej.nih.gov/ij/.

[23]A. Manhard, M. Balden, S. Elgeti, Quantitative microstructure and defect density analysis of polycrystalline tungsten reference samples after different heat treatments, Practical Metallography, 52 (2015) 437-466.

[24]W.F. Hosford, Microstructural changes during deformation of (011) fiber-textured metals, Trans. Metall. Soc. AIME 230 (1964) 12-15.

[25]E. Lassner, W.D. Schubert, Tungsten: Properties, chemistry, technology of the element, alloys, and chemical compounds, Springer Science \& Business Media, 1999.

[26]J.R. Davis, Tensile testing, ASM International, 2004.

[27]R. Danzer, P. Supancic, J. Pascual, T. Lube, Fracture statistics of ceramics-Weibull statistics and deviations from Weibull statistics, Eng. Fract. Mech. 74 (2007) 2919-2932.

[28]E.S. Lindquist, Strength of materials and the Weibull distribution, Probabilist. Eng. Mech. 9 (1994) 191-194.

[29]J.S. Kim, B.J. Yum, Selection between Weibull and lognormal distributions: A comparative simulation study, Comput. Stat. Data Anal. 53 (2008) 477-485.

[30]A.G. Evans, Structural reliability: A processing-dependent phenomenon, J. Am. Ceram. Soc. 65 (1982) 127-137.

[31]D.S. Sivia, J. Skilling, Data analysis: a Bayesian tutorial, OUP Oxford, 2006.

[32]W. von der Linden, V. Dose, U. von Toussaint, Bayesian probability theory: Applications in the physical sciences, Cambridge University Press, 2014.

[33]U. von Toussaint, Bayesian inference in physics, Rev. Mod. Phys. 83 (2011) 943-998. 
[34]D.J.C. MacKay, Information theory, inference and learning algorithms, Cambridge University Press, 2003.

[35]D. Lee, Fracture of drawn tungsten wires, Metall. Trans. A 6 (11) (1975) 2083-2088.

[36]F.J. Humphreys, M. Hatherly, Recrystallization and related annealing phenomena, Pergamon, 1995.

[37]P. Makarov, K. Povarova, Development of tungsten-based vacuum melted and powder structural alloys, Int. J. Refr. Met. Hard Mater. 20 (2002) 277-285.

[38]A. Alfonso, D. Juul Jensen, G.N. Luo, W. Pantleon, Recrystallization kinetics of warm-rolled tungsten in the temperature range $1150-1350^{\circ} \mathrm{C}$, J. Nucl. Mater. 455 (2014) 591-594.

[39]A. Alfonso, D. Juul Jensen, G.N. Luo, W. Pantleon, Thermal stability of a highly-deformed warmrolled tungsten plate in the temperature range 1100-1250 ${ }^{\circ}$ C, Fusion Eng. Des. 98-99 (2015) 1924-1928.

[40]A. Evans, Perspective on the development of high-toughness ceramics, J. Am. Ceram. Soc. 73 (1990) 187-206.

[41]R. Ritchie, Mechanisms of fatigue-crack propagation in ductile and brittle solids, Int. J. Fract. 100 (1999) 55-83.

[42]E.J. Horwath, The high strain rate deformation of tungsten single crystals, U.S. Army Research Laboratory, 1994, pp. 4-8.

[43]P.F. Browning, C.L. Briant, K. Rajan, B.A. Knudsen, An analysis of splitting failures during the drawing of tungsten wire, Eng. Fail. Anal. 2(2) (1995) 105-115.

[44]S.M. Weygand, H. Riedel, B. Eberhard, G. Wouters, Numerical simulation of the drawing process of tungsten wires, Int. J. Refract. Metals Hard Mater. 24 (2006) 338-342.

[45]P.W. Bridgman, The stress distribution at the neck of a tension specimen, Trans. ASM 32 (1944) 553-574.

[46]W.S. Lee, G.L. Xiea, C.F. Lin, The strain rate and temperature dependence of the dynamic impact response of tungsten composite, Mater. Sci. Eng. A 257 (1998) 256-267.

[47]W.S. Lee, C.F. Lin, G.L. Xiea, Dynamic shear deformation and failure behaviour of pure polycrystalline tungsten, Mater. Sci. Eng. A 247 (1998) 102-112.

[48]Q. Wei, L.J. Kecskes, Effect of low-temperature rolling on the tensile behavior of commercially pure tungsten, Mater. Sci. Eng. A 491 (2008) 62-69.

[49]W.J. Yuan, F. Zhou, Z.L. Zhang, Y.J. Su, L.J. Qiao, W.Y. Chu, An analysis on necking effect and stress distribution in round cross-section specimens of pure copper with different diameters, Mater. Sci. Eng. A 561 (2013) 183-190.

[50]J. Riesch, M. Aumann, J.W. Coenen, H. Gietl, G. Holzner, T. Höschena, P. Huber, M. Li, C. Linsmeier, R. Neu, Chemically deposited tungsten fibre-reinforced tungsten-the way to a mock-up for divertor applications, Nucl. Mater. Energy 9 (2016) 75-83. 